\title{
Research of the Quality of Quarry Dumpers En- gine Crankshafts Sliding Bearings of Various Manufacturers
}

\author{
Alexander Korotkov ${ }^{1 *}$, Lidiya Korotkova ${ }^{1}$, and Denis Vidin ${ }^{1}$ \\ ${ }^{1}$ T.F. Gorbachev Kuzbass State Technical University, 650000, 28 Vesennyaya St., Kemerovo, Russia
}

\begin{abstract}
Sliding bearings are an important part of many large and critical components. They are widely used in power equipment, high-capacity pumps, compressors, electric motors and internal combustion engines (ICE). As a rule, sliding bearings include an antifriction bushing, part of the shaft surface (bearing journal), and a layer of oil between them. These are complex and critical parts in which there may occur dangerous defects, and which directly affect the durability, accuracy and reliability of the entire unit. To ensure high reliability of the equipment with sliding bearings applied in complex equipment, it is necessary to provide the quality control and sufficient level of monitoring of the technical condition, as well as diagnosis of emerging defects. This paper presents a comparative analysis of the internal combustion engines sliding bearings quality of various manufacturing companies. It gives operational properties of bearings depending on the compositional composition. The results of chemical analysis of the base, the cover and intermediate layers of the ICE liners are presented here. We have also made recommendations to increase the operational performance of sliding bearings.
\end{abstract}

\section{Introduction}

Sliding bearings are critical parts of an internal combustion engine, failure of which leads to its complete stop and often to the following expensive repairs. Bushings are high-tech products made of composite material, having a complex construction and precise dimensions.

Internal combustion engines are characterized by cyclic loading of bearings due to variable pressure in the cylinder as well as inertial forces caused by the moving parts.

The vast majority of the crankshafts of the engines of modern cars rotate in the sliding bearings, so called bushings.

Long and reliable work of the sliding bearing is achieved by providing a number of indicators, including fatigue strength, wear resistance, cavitation resistance, adaptation, resistance to setting, absorption capacity.

Rotating components of internal combustion engines are equipped with sliding bearings, performing different functions [1]:

*Corresponding author: korotkov.a.n@mail.ru 
- The main bushings support the crankshaft and rotate it. They are installed in the cylinder block, and each bushing consists of the upper and lower semi-rings. As a rule there is a groove for lubrication and an opening for the supply of oil on the inner surface of the upper semi-ring.

- Connecting rod bushings ensure the rotation of the crank pin that rotates the crankshaft. Connecting rod bushings are installed in the lower end of the connecting rod.

- Thrust rings prevent axial movement of the shaft. In many cases, the thrust rings are part of one of the main bushings. Such combined bearings are called collar liners.

- The bushings of the connecting rod upper head ensure the rotation of the piston pin connecting the piston with the connecting rod.

- The camshaft bushings support and rotate it. They are installed on the top of the cylinder block head.

The sliding bearings are lubricated with engine oil constantly supplied in sufficient quantity to their surface and providing hydrodynamic friction mode. Fluid (hydrodynamic) friction is characterized by a pressurized oil film separating the bearing and shaft surfaces.

There is no direct contact between the surfaces in the hydrodynamic mode. This is ensured by the force of the hydrodynamic pressure emerging in the oil, which is forced through the converging gap (oil wedge) formed by the bearing and shaft surfaces.

The working conditions of the sliding bearings are classified as heavy stress. They operate in a mixed friction mode, when direct contact occurs during operation alternating with hydrodynamic friction [2].

The oil film contributes to the distribution of the force applied to the bearing, thus preventing local load concentration [3].

However, under certain conditions, hydrodynamic friction mode is changed to a mixed one. These conditions are as follows [1]:

- Insufficient oil flow;

- High loads;

- Low viscosity of oil;

- Overheating of the oil, further reducing its viscosity;

- High roughness of bearing and shaft surfaces;

- Oil contamination;

- Deformation and geometric defects of the bearing, its nest or shaft.

A mixed friction mode can lead to scuffing, increased wear of the bearing and even gripping the shaft [4].

Cyclic bearing loads can lead to its destruction due to fatigue of the material.

The following requirements apply to materials for sliding bearings [1]:

- Fatigue strength (maximum load) is the maximum cyclic load that the bearing can withstand for an unlimited number of cycles. Exceeding this load leads to the formation of fatigue cracks in the material.

- Resistance to setting (compatibility) - the ability of the bearing material to resist welding to the shaft material during direct physical contact between them.

- Wear resistance - the ability of the bearing material to maintain its dimensions despite the presence of abrasive particles in the oil as well as under conditions of metal contact with the shaft.

- Adaptation - the ability of the bearing material to compensate for small geometric defects in the shaft and the seat due to minor local wear or plastic deformation.

- Absorption capacity - the ability of the bearing material to capture small foreign particles that circulate with the oil.

- Corrosion resistance - the ability of the bearing material to resist the chemical influence of the oxidized or contaminated oils. 
- Cavitation stability - the ability of the bearing material to withstand shock loads produced by collapsing cavitation bubbles (bubbles are formed because of a sudden drop in the pressure of the oil flow).

\section{Materials and methods}

Depending on the operating conditions, the design of the sliding bearings is chosen. It is possible to distinguish two basic designs of bearings used in heavy stress conditions - these are bimetallic and trimetallic bearings $[5,6,7]$.

\section{Properties of bearing materials}

Comparative properties of the most popular bearing materials, depending on the structure composition, are shown in Table 1 [8].

As we may see from Table 1, properties that characterize strength and softness are combined in different proportions for different materials.

Sufficient soft antifriction properties of trimetal are limited by the coating thickness, which should be no more than $12 \mu \mathrm{m}$. If a geometric defect or foreign particles exceed the thickness of the coating, its antifriction properties drop sharply $[9,10]$.

The soft properties of bimetal are somewhat lower than those of trimetal, but they are not limited to coating thickness, so bimetallic bearings are capable of adapting to various geometric defects [6].

On the other hand, the fatigue strength (maximum load) of bimetallic bearings is lower (40-50 MPa) than for trimetallic bearings (60-70 MPa).

To control the quality of sliding bearings (bushings), a methodology has been developed to meet the standard samples. This includes the following steps:

- layer-by-layer control of the chemical composition of the researched alloys;

- carrying out metallographic tests to determine the number and depth of layers of applied coatings;

- layer-by-layer control of the applied coatings and the base of the bushing microhardness distribution.

Table 1 Operational properties of bearings depending on the composition of the composition

\begin{tabular}{|l|c|c|c|}
\hline \multicolumn{1}{|c|}{ Property } & $\begin{array}{c}\text { Bimetal } \\
\text { Without Si }\end{array}$ & $\begin{array}{c}\text { Bimetal } \\
\text { With Si }\end{array}$ & $\begin{array}{c}\text { Trimetal with lead } \\
\text { coating }\end{array}$ \\
\hline Fatigue strength, MPa & 40 & 55 & $60-70$ \\
\hline $\begin{array}{l}\text { Compatibility with the } \\
\text { steel shaft }\end{array}$ & very good & good & $\begin{array}{c}\text { excellent (until the } \\
\text { coating has been worn } \\
\text { off) }\end{array}$ \\
\hline $\begin{array}{l}\text { Compatibility with the } \\
\text { cast iron shaft }\end{array}$ & satisfactory & very good & $\begin{array}{c}\text { excellent (until the } \\
\text { coating has been worn } \\
\text { off) }\end{array}$ \\
\hline Wear resistance & good & very good & satisfactory \\
\hline $\begin{array}{l}\text { Absorption capacity } \\
\text { for particles larger than } \\
12 \text { mm }\end{array}$ & very good & good & excellent \\
\hline $\begin{array}{l}\text { Absorption capacity } \\
\text { for particles smaller } \\
\text { than } 12 \text { mm }\end{array}$ & very good & good & bad \\
\hline $\begin{array}{l}\text { Adaptation to geomet- } \\
\text { ric defects larger than } \\
12 \mu \mathrm{m}\end{array}$ & very good & good & \\
\hline
\end{tabular}




\begin{tabular}{|l|c|c|c|}
\hline \multicolumn{1}{|c|}{ Property } & $\begin{array}{c}\text { Bimetal } \\
\text { Without Si }\end{array}$ & $\begin{array}{c}\text { Bimetal } \\
\text { With Si }\end{array}$ & $\begin{array}{c}\text { Trimetal with lead } \\
\text { coating }\end{array}$ \\
\hline $\begin{array}{l}\text { Adaptation to geomet- } \\
\text { ric defects smaller than } \\
12 \mu \mathrm{m}\end{array}$ & very good & good & excellent \\
\hline
\end{tabular}

Conducting chemical analysis of alloys

To conduct a layer-by-layer chemical analysis of metal coatings and the base of the bushings, we used an $Q 4 T A S M A N$ optic emission spectrometer.

Atomic emission spectrometers apply the principles of atomic emission spectroscopy (AESA). These devices are the most common analytical instruments in the world and in our country. They are designed for analysis (most often elemental analysis) of the composition of various substances in different aggregate states.

Metallographic studies

These included preparation of samples and direct study the microstructure.

Preparation of samples for metallographic studies

It is one of the most important stages in carrying out metallographic studies of the metals' structure and mechanical properties, and it is very important in metallography. Metallographic preparation of samples is a process of obtaining quality samples for research. The quality of sample preparation directly affects the quality of research results $[8,9]$.

We have to provide a number of conditions to conduct metallographic studies in order to determine the number and depth of layers of coatings applied on bearings:

- to cut samples with minimal residual deformations;

- not to damage surface layers during the preparation of thin sections;

- to form a high quality of the researched surface of the samples.

Determining the number and thickness of the layers

To assess the number and thickness of the applied layers of metal coatings on the bushing, we used a special inverted optical metallographic microscope, EPIQUANT, which allows accurate measurements of both the depth of the applied coating and the quantitative phase size by the quantitative metallography method at X1500 magnification.

Measuring the thicknesses of the sliding bearing layers was carried out with the help of an eyepiece micrometer, with glass with a printed scale inserted in it.

Measurement of microhardness

Microhardness was measured by pressing a diamond pyramid according to Vickers method. The PMT-3 microhardness meter allowed placing the imprint in a separate grain, phase or layer.

Fig. 1 and Fig. 2 show the determination of the hardness of individual bearing layers. The microhardness meter allows to make prints and determine microhardness at any point of the layer. Microhardness is determined here at a load of $100 \mathrm{~g}$. To determine the microhardness of a thin upper layer, we used the load of $50 \mathrm{~g}$.

\section{Results and discussion}

This paper covers the results of studying internal combustion engines trimetal bushings of different sizes, types and manufacturers. A comparative evaluation of the quality of the bushings was carried out basing on the results of chemical analysis of the layers, their thickness and microhardness.

The research was conducted on the samples of sliding bearings, the list of which is given in Table 2. 
The results of the studies are summarized in Tables 3 - 5. Based on the presented results, it is possible to carry out a comparative analysis of the bearings' quality, based on their structure, chemical composition of layers and microhardness.

The conducted metallographic studies made it possible to notice that all the samples under research (Figures 1 and 2) include three basic layers: a steel base, a copper alloy bushing (intermediate layer), and a whitemetal cover layer. In the design of the examined bearings, we found protective tin layers of a shallow depth of several micrometers (coating), as well as a nickel gasket (barrier) between the cover layer and the bearing shell. Thus, the design of all bearings is the same.

Table 2. List of researched samples

\begin{tabular}{|c|c|c|}
\hline No. of researched sample & Size of the bearing & Manufacturer's code \\
\hline 1 & 205160 & Cummins POL \\
\hline 2 & 205160 & Cummins CCEC \\
\hline 3 & 205140 & Cummins CCEC \\
\hline 4 & 205840 & WETZ \\
\hline 5 & 205840 & WETZ \\
\hline
\end{tabular}

Table 3. Results of studying bushings bases

\begin{tabular}{|c|c|c|c|c|c|c|c|c|c|c|c|}
\hline \multirow[b]{2}{*}{ № } & \multicolumn{11}{|c|}{ Steel chemical analysis } \\
\hline & $\mathbf{C}$ & Si & Mn & $\mathbf{P}$ & $\mathbf{S}$ & $\mathrm{Cr}$ & $\mathbf{N i}$ & $\mathbf{C u}$ & Al & Sn & $\begin{array}{c}\mathrm{HV}, \\
\mathrm{Kgf} / \\
\mathbf{m m} 2\end{array}$ \\
\hline 1 & $\begin{array}{c}0,05 \\
3\end{array}$ & $\begin{array}{c}<0,001 \\
5\end{array}$ & $\begin{array}{c}0,27 \\
5\end{array}$ & $\begin{array}{c}0,003 \\
2\end{array}$ & $\begin{array}{c}0,004 \\
6\end{array}$ & 0,025 & $\begin{array}{c}0,005 \\
3\end{array}$ & $\begin{array}{c}0,03 \\
6\end{array}$ & $\begin{array}{c}0,02 \\
8\end{array}$ & $\begin{array}{c}0,0 \\
03\end{array}$ & $\begin{array}{l}164- \\
210\end{array}$ \\
\hline 2 & $\begin{array}{c}0,12 \\
4\end{array}$ & 0,0020 & $\begin{array}{c}0,58 \\
0\end{array}$ & $\begin{array}{c}0,001 \\
0\end{array}$ & $\begin{array}{c}0,001 \\
0\end{array}$ & 0,037 & 0,038 & $\begin{array}{c}0,05 \\
3\end{array}$ & $\begin{array}{c}0,01 \\
6\end{array}$ & $\begin{array}{c}0,0 \\
17\end{array}$ & $\begin{array}{c}183- \\
194\end{array}$ \\
\hline 3 & $\begin{array}{c}0,12 \\
6\end{array}$ & 0,0030 & $\begin{array}{c}0,55 \\
7\end{array}$ & $\begin{array}{c}0,001 \\
0\end{array}$ & $\begin{array}{c}0,001 \\
5\end{array}$ & 0,037 & 0,026 & $\begin{array}{c}0,07 \\
2\end{array}$ & $\begin{array}{c}0,01 \\
6\end{array}$ & $\begin{array}{c}0,0 \\
17\end{array}$ & $\begin{array}{c}170- \\
183\end{array}$ \\
\hline 4 & $\begin{array}{c}0,15 \\
8 \\
\end{array}$ & 0,014 & $\begin{array}{c}0,36 \\
3 \\
\end{array}$ & $\begin{array}{c}0,005 \\
2 \\
\end{array}$ & $\begin{array}{c}0,005 \\
4 \\
\end{array}$ & $\begin{array}{c}0,009 \\
3 \\
\end{array}$ & $\begin{array}{c}0,001 \\
5 \\
\end{array}$ & $\begin{array}{c}0,01 \\
3 \\
\end{array}$ & $\begin{array}{c}0,03 \\
2 \\
\end{array}$ & $\begin{array}{c}0,0 \\
02 \\
\end{array}$ & $\begin{array}{l}186- \\
214 \\
\end{array}$ \\
\hline 5 & $\begin{array}{c}0,14 \\
0\end{array}$ & 0,020 & $\begin{array}{c}0,37 \\
1\end{array}$ & $\begin{array}{c}0,004 \\
9\end{array}$ & $\begin{array}{c}0,005 \\
3\end{array}$ & $\begin{array}{c}0,009 \\
8\end{array}$ & $\begin{array}{c}0,004 \\
5\end{array}$ & $\begin{array}{c}0,03 \\
1\end{array}$ & $\begin{array}{c}0,03 \\
5\end{array}$ & $\begin{array}{l}0,0 \\
34\end{array}$ & $\begin{array}{c}159- \\
190\end{array}$ \\
\hline
\end{tabular}

Table 4. Results of studying bushings coating layers

\begin{tabular}{|c|c|c|c|c|c|c|c|}
\hline \multirow{2}{*}{ № } & \multicolumn{7}{|c|}{ Whitemetal chemical analysis } \\
\cline { 2 - 8 } & $\mathbf{P b}$ & Sn & $\mathbf{F e}$ & $\mathbf{N i}$ & $\mathbf{C u}$ & $\begin{array}{c}\text { HV, } \\
\mathbf{K g f} / \mathbf{m m} 2\end{array}$ & $\mathbf{h , ~} \mathbf{\mu m}$ \\
\hline 1 & $>26,40$ & $>26,40$ & 0,310 & 20,24 & 26,28 & $16-25$ & 25 \\
\hline 2 & $>26,40$ & $>26,40$ & 0,284 & 27,62 & 18,87 & $22,4-20,5$ & 16 \\
\hline 3 & 26,40 & 5,707 & 0,047 & 2,588 & 65,09 & $21-20,5$ & 16 \\
\hline 4 & 26,40 & 2,460 & 0,035 & 5,209 & 65,75 & $18,5-19,3$ & 16 \\
\hline 5 & 26,40 & 1,709 & 0,033 & 4,014 & 67,69 & $22,4-21,9$ & 16 \\
\hline
\end{tabular}


Table 5. Results of studying bushings intermediate layer

\begin{tabular}{|c|c|c|c|c|c|c|c|}
\hline \multirow{2}{*}{ № } & \multicolumn{7}{|c|}{ Bronze chemical analysis } \\
\cline { 2 - 8 } & $\mathbf{P b}$ & $\mathbf{S n}$ & $\mathbf{F e}$ & $\mathbf{N i}$ & $\mathbf{C u}$ & $\begin{array}{c}\mathbf{H V}, \\
\text { Kgf / mm2 }\end{array}$ & h, $\boldsymbol{\mu m}$ \\
\hline 1 & 21,61 & 2,828 & 0,198 & 0,018 & 75,32 & $86-107$ & 520 \\
\hline 2 & 22,57 & $<2,000$ & 0,045 & 0,078 & 75,28 & $106-128$ & 360 \\
\hline 3 & 25,95 & 2,921 & 0,079 & 0,017 & 71,00 & $77,2-100$ & 360 \\
\hline 4 & 26,27 & 1,680 & 0,021 & 0,597 & 71,30 & $110-135$ & 320 \\
\hline 5 & 26,40 & 1,397 & 0,024 & 0,465 & 71,58 & 122 & 304 \\
\hline
\end{tabular}

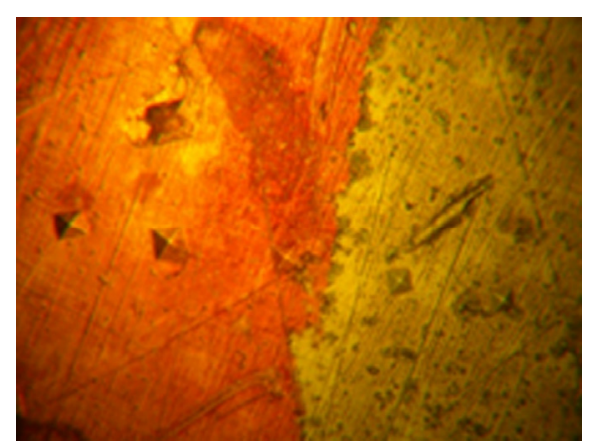

Fig. 1. Imprint of an indenter when measuring the microhardness of a layer and a substrate.

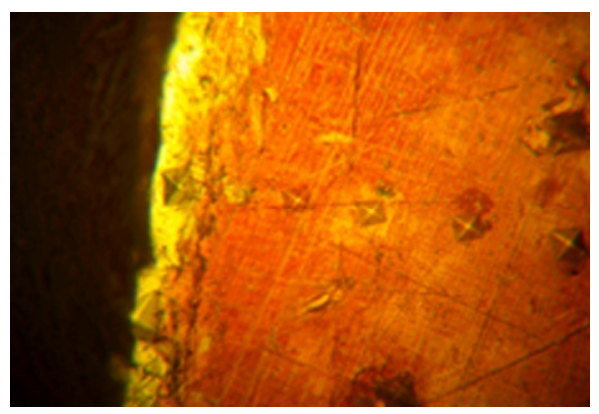

Fig. 2. Imprint of the indenter of the microhardness meter when measuring a thin layer of whitemetal.

The base for all studied bushings is made of low-carbon, high-quality steel. The method of manufacturing is cold-rolled steel with fine-grained ferritic microstructure. Its microhardness is $160-210 \mathrm{HV}$ (see Table 3).

The conducted research made it possible to identify some differences in the chemical composition, depth, and microhardness of the working layers (see Tables 4 and 5).

Thus, in the production of the coating layer, they use lead-tin plies (samples No. 1, 2) or leaded whitemetals (samples No. 3, 4, 5). In all the samples studied, the depth of the cover layer is in the range of admissible values of $12-25 \mu \mathrm{m}$. The chemical composition of whitemetals does not make any significant influence on microhardness (see Table 4).

The intermediate layer in all the samples studied is a tin lead-containing cast bronze. By the chemical composition, bronze can be identified according to State Standard (GOST) 613-79 as brands approximating BrO3C22 and BrO5S25 [15]. This shows that the chemical composition of the intermediate layer of the ICE bushings of various manufacturing companies is very close. The uniformity of the alloys has been proved by metallographic studies 
and similar microhardness values in the range of 100-160 HV (two-phase microstructure) (Table 5).

Thus, basing on the comparative analysis of the quality of the ICE bushings of different manufacturers, it can be concluded that they are close in structure and chemical composition, namely:

- Cummins POL: lead-tin-based whitemetal - nickel interlayer - tin lead-containing bronze.

- Cummins CCEC: lead-tin-based whitemetal - nickel interlayer - tin lead- containing bronze.

- WETZ (domestic manufacturer): lead-based whitemetal - nickel interlayer - tin leadcontaining bronze.

As a result, we can conclude that all bearings are suitable for operation, and it should be noted that the ICE sliding bearings of domestic manufacturer (WETZ) are not inferior in quality to foreign analogues (Cummins POL, Cummins CCEC).

It should be borne in mind that the service life of ICE bushings is determined not only by their quality, but, to a large extent, by the conditions of their operation. In this regard, it is reasonable to formulate conditions for the non-failure operation of sliding bearings.

\section{Recommendations to improve the performance of bearings}

To ensure high performance of the internal combustion engine bushings in the course of operation, a number of conditions related to the quality of the bearing parts in the delivery state and during operation must be fulfilled. This will make internal combustion engines work for a long time (up to 1.5 million $\mathrm{km}$ ). However, to ensure such a service life, the following requirements must be met:

1. Correct installation of bearings.

2. High quality of a journal contours crankshaft processing.

3. Ensuring the required routine maintenance.

4. Meeting the requirements on the recommended oil change intervals and the use of oils with the suitable grades of SAE viscosity and the API quality standard.

5. Prevent the coolant and fuel from entering the engine oil.

6. Monitoring of engine operating conditions to avoid overloads, high speed and engine overheating.

How long is the period of engine bearings trouble-free operation depends on the implementation of the quality standard, which should regulate the fault detection tests.

\section{Conclusion}

1. There has been carried out a patent-literature analysis on the standard designs of sliding bearings bushings, in terms of chemical composition, technology of production of crankshaft bushings for combustion engines.

2. We have studied typical designs of ICE crankshaft bushings of various manufacturers: materials for sliding bearings, requirements for these materials and properties of bearing materials.

3. We have developed the methodology for quality control of the ICE bushings. It includes chemical analysis of alloys, metallographic studies, measurement of microhardness, measurement of the layers depths.

4. As a result of approbation of the developed technique for quality control of internal combustion engines crankshafts bearings, it has been revealed that all the researched crankshaft bushings are trimetallic in structure. 
5. The comparative analysis of the ICE bushings of various manufacturing companies (Cummins POL, Cummins CCEC, WETZ) has shown that they differ from each other in chemical composition, depth and microhardness of the working layers:

5.1.Cummins POL: lead-tin-based whitemetal - nickel interlayer - tin lead-containing bronze.

5.2.Cummins CCEC: lead-tin-based whitemetal - nickel interlayer - tin lead-containing bronze.

5.3.WETZ (domestic manufacturer): lead-based whitemetal - nickel layer - tin leadcontaining bronze.

6. On the basis of a comparative analysis of the quality of the internal combustion engines bushings of different manufacturers, it has been concluded that all of them are suitable for operation.

7. Domestic manufacturerls (WETZ) sliding bearings for internal combustion engines are not inferior in quality to foreign analogues (Cummins POL, Cummins CCEC).

\section{References}

1. D. Kopeliovich, Inserts for the engine - details are critical. (ABS-Auto. The first autoservice magazine.)

2. S.S. Kim, H.N. Yu, I.U. Hwang, D.G. Lee, S.N. Kim, K. Suzuki, H. Sada, Tribology Letters, 35:3, 211 (2009)

3. O.G. Zavyalov, Y.V. Alyabyeva, O.S. Savchenkova, Journal of Friction and Wear, 30:4, 235 (2009)

4. A. Zeren, Materials and Design, 28:8, 2344 (2007)

5. GOST 28813-90 Bearings of sliding. Metal multilayer materials for thin-walled plain bearings. Publishing Standards, 11 (1990)

6. GOST ISO 4383-2006 Bearings of sliding. Multilayer materials for thin-walled plain bearings, 8 (2009)

7. L. I. Simma Chemical and Petroleum Engineering, 45:9:10, 649 (2009)

8. F.H. Burumkulov, S.A. Velichko, P.V. Chumakov, Proceedings of GOSNITI, 111:2, $142(2013)$

9. A. N. Korotkov, L. P. Korotkova, D. V. Vidin, S.V. Lashchinen, O.V. Frolova, KuzGTU, Bul. 1:113, 119 (2016)

10. B. Leszczyńska-Madej, M. Madej, Archives of Metallurgy and Materials, 56:3, 805 (2011) 